\title{
Dilemma in Diabetes Care Relates to Its Complications: Strategies for Prevention
}

\author{
Anil K. Mandal ${ }^{*}$, Linda Hiebert ${ }^{2}$ \\ Correspondence: amandal@med-spec.com \\ 'Consultant in Nephrology, Courtesy Clinical Professor of Medicine,University of Florida, Gainesville, Florida, USA. \\ ${ }^{2}$ Professor of Veterinary Biomedical Sciences, University of Saskatchewan, Saskatoon, Canada.
}

\begin{abstract}
The dilemma concerning the prevailing classification of Type 1 and Type 2 diabetes is a serious hindrance to effective diabetes care. Many patients who are classified with Type 2 diabetes have symptoms and require treatment similar to those classified with Type 1 diabetes. In addition, patients are often diagnosed with diabetes as a result of elevated fasting blood glucose instead of 2-hour postprandial glucose levels or oral glucose tolerance tests. The misdiagnosis of diabetes accompanied by prescription of oral hypoglycemic agents or antihypertensive therapy, have caused unwarranted health problems in people who may not have diabetes.

In this article, patients are presented who illustrate the misdiagnosis of diabetes and the need of proper testing to uncover diabetes. Additional case histories indicate the effect that oral hypoglycemic agents and antihypertensive medications may have on patient health. Suggestions are made regarding proper diagnosis and care. In patients with established diabetes, adequate control of glycemia with insulin, diet restriction and weight reduction, fundamental to prevention of microvascular and macrovascular complications, is stressed. Hospitalizations are preventable if professionals spend time explaining details of diabetic care to patients thereby enabling them to take full responsibility of their illness. Glucose control with insulin therapy, concomitantly with means for weight reduction in obese individuals, must be discussed in a repetitive fashion with the patient. Uncontrolled diabetes, resulting in frequent hospitalizations for a variety of complications, has markedly escalated the cost of diabetic care. Patient education and cooperation are the cornerstone of successful diabetes therapy and the mainstay of prevention of diabetes complications. Thereby, the cost of diabetes care will be reduced.

The classification of Type 1 and Type 2 diabetes conveys little to the patients about diabetes which is a potentially devastating disease, nevertheless, with full attention to glucose control, healthy living is attainable. Utmost care should be taken to identify if the person does or does not have diabetes by appropriate testing and attention to proper therapy.
\end{abstract}

Keywords: Diabetes, insulin therapy, 2-hour postprandial glucose, glycosylated hemoglobin, oral glucose tolerance test

\section{Introduction}

Diabetes is a chronic disease that occurs either when the pancreas does not produce enough insulin or when the body cannot effectively use the insulin it produces. Insulin is a hormone that regulates blood sugar. Hyperglycemia or raised blood sugar is a common effect of uncontrolled diabetes and over time, leads to serious damage to many of the body's systems, especially the nerves and blood vessels (WHO) [1]. The World Health Organization (WHO) classifies diabetes as follows:

Type 1 diabetes, previously known as insulin-dependent, juvenile or childhood-onset, is characterized by deficient insulin production and requires daily administration of insulin.

Type 2 diabetes, formerly called non-insulin dependent or adult-onset, results from the body's ineffective use of insulin. Type 2 diabetes comprises $90 \%$ of diabetic patients around the world, and is largely the result of excess body weight and physical inactivity. Symptoms may be similar to Type 1 diabetes, but often less marked. As a result, the disease may be diagnosed several years later, once complications have already arisen.

Gestational diabetes is hyperglycemia with onset or first recognition during pregnancy

The prevailing classification of diabetes, into Type 1 and Type 2 diabetes, limits a complete understanding of diabetes and creates a serious dilemma in treatment. According to the WHO diabetes fact sheet (2012), until recently, Type 2 diabetes was seen only in adults but it

C 2012 Mandal et al; licensee Herbert Publications Ltd. This is an open access article distributed under the terms of Creative Commons Attribution License (http://creativecommons.org/licenses/by/3.0),This permits unrestricted use, distribution, and reproduction in any medium, provided the original work is properly cited. 
is now also occurring in children. Because this does not follow the current classification of diabetes, it may be more appropriate to connote the diagnosis of diabetes rather than Type 1 or Type 2 diabetes. This connotation of diagnosis is quite appropriate as an undefined number of adults appear in the emergency rooms of local hospitals with a history of polyuria and polydipsia mimicking Type 1 diabetes and consequently are found to have severe hyperglycemia. Furthermore, these patients require daily insulin injections to keep hyperglycemia under control and to remain symptom free, identical to those with Type 1 diabetes (WHO).

Typically adults with elevated fasting blood glucose (FBG) levels $>126 \mathrm{mg} / \mathrm{dL}$ (> 7mmol/L) irrespectively are diagnosed with Type 2 diabetes and automatically prescribed one or more oral hypoglycemic agents $(\mathrm{OHA})$ by doctors or more often by the physician-assistants or nurse practitioners. These OHA are biguanides (metformin), sulfonylurea, (glyburide, glipizide or glimepiride), thiazolidinedone (rosiglitazone or pioglitazone) or more recently dipeptidylpeptidase-4 inhibitor (sitagliptin or saxagliptin).

Diabetes is defined by a 2-hour postprandial glucose (2-hPPG) level of $>200 \mathrm{mg} / \mathrm{dL}$ ( $>11.1 \mathrm{mmol} / \mathrm{L})$, determined by an oral glucose tolerance test, according to WHO [1] and others [2]. In most patients, since a diagnosis of Type 2 diabetes is made on the basis of FBG of $>126 \mathrm{mg} / \mathrm{dL}$ (7 $\mathrm{mmol} / \mathrm{L}$ ) or glycosylated hemoglobin $\left(\mathrm{HbA}_{1} \mathrm{c}\right)>6.5 \%$, and not by 2-hPPG, it is difficult to ascertain how many patients with the diagnosis of Type 2 diabetes actually have welldefined diabetes.

The purpose of this communication is to develop a critique of the prevailing classification of diabetes, into Type 1 and Type 2 diabetes, in order to improve the outcomes associated with uncontrolled diabetes. In addition, diabetes will be compared to merely elevated, fasting blood glucose levels (hyperglycemia). Common causes of fasting hyperglycemia are those induced by drugs, such as thiazide diuretics, steroids, or tacrolimus, mimicking diabetes. In this communication, the profile of several patients will be presented to exemplify misdiagnosis of diabetes and overenthusiastic prescription of OHA for the sake of prevention of diabetes. In addition, relevant testing to establish or exclude diabetes and individualization of therapy based on 2hPPG will be described. The author's (AKM) practice is limited to adults with diabetes.

\section{Patient presentations}

Patient \#1: This patient reveals ambiguities in the diagnosis of diabetes. A 70 y white male, weighing 261 pounds, was referred to the author in April of 2007 for diabetic neuropathy and pain and swelling of the lower extremities. His medication at the first visit consisted of dutasteride 0.5 mg PO daily, gabapentin 300 mg PO daily, furosemide 20 mg PO daily, pioglitazone 15 mg PO daily, lansoprazole
$40 \mathrm{mg}$ PO daily, amitriptyline $25 \mathrm{mg}$ at bedtime daily, and simvastatin $20 \mathrm{mg}$ PO daily. He showed prominent varicose veins in both lower extremities, and decreased deep tendon reflexes suggesting neuropathy. His sitting blood pressure (BP) was $120 / 80 \mathrm{mmHg}$. Initial laboratory could not be obtained except for $\mathrm{HbA}_{1} \mathrm{c}$ of $5.8 \%$. He was treated for Type 2 diabetes with pioglitazone. The first action was to discontinue furosemide for 5 days and obtain FBG, 2-hPPG, $\mathrm{HbA}_{1}$, and renal function parameters. They were $107 \mathrm{mg} /$ $\mathrm{dL}(5.94 \mathrm{mmol} / \mathrm{L}), 145 \mathrm{mg} / \mathrm{dL}$ ( $8.05 \mathrm{mmol} / \mathrm{L}), 6.0 \%$ and eGFR $>60 \mathrm{ml} / \mathrm{min}$, respectively. Thereafter, pioglitazone was put on hold for 8 days. After 8 days, FBG, 2-hPPG, HbA, and $24 \mathrm{~h}$ urinary studies were done. Results were $108 \mathrm{mg} / \mathrm{dL}$ (6 $\mathrm{mmol} / \mathrm{L}), 121 \mathrm{mg} / \mathrm{dL}(6.72 \mathrm{mmol} / \mathrm{L})$, and $6.1 \%$, respectively. Thus, 2-hPPG was lower without pioglitazone than with pioglitazone. FBG and $\mathrm{HbA}_{1} \mathrm{c}$ were the same with and without pioglitazone. His 24-hour urine protein was 150 $\mathrm{mg}$ and creatinine clearance $158.4 \mathrm{ml} / \mathrm{min}$.

Thus, based on laboratory findings, it was safe to state that the patient did not have diabetes. The question remains, why did he develop neuropathy? Could he have pre-diabetes with a high insulin response? A 4-hour oral glucose tolerance test (OGTT) was done and results are shown in Table 1.

Surely OGTT was abnormal. The 1-hour glucose level was consistent with diabetes but this increase was not sustained. He showed a high insulin response with a decrease in glucose levels after 1 hour. He was recommended a 1600 calorie diabetes diet. He is doing well. It is important to note that the patient was needlessly taking pioglitazone, which causes swelling of the lower extremities.

Patient \#2: This patient exemplifies that complete testing for glycemic parameters in an obese individual may uncover diabetes.

A 78 y African American male, weighing 228 pounds, had an office visit with the author during the first week of May, 2008. The patient had a history of uncontrolled hypertension, but no history of diabetes. Sitting and standing BPs were $140 / 90 \mathrm{mmHg}$ and 150/90 $\mathrm{mmHg}$, respectively. Medication

Table 1. Results from a 4-hour Glucose Tolerance Test (Patient 1)

\begin{tabular}{|c|c|c|}
\hline$\frac{\text { Time after Glucose Ingestion }}{\text { (hours) }}$ & $\frac{\text { Glucose }}{(\mathrm{mg} / \mathrm{dL})}$ & $\frac{\text { Glucose }}{(\mathrm{mmol} / \mathrm{L})}$ \\
\hline FBG & 116 & 6.4 \\
\hline 1 & 214 & 11.8 \\
\hline 2 & 113 & 6.27 \\
\hline 3 & 105 & 6.0 \\
\hline 4 & 104 & 5.7 \\
\hline
\end{tabular}

FBG = Fasting Blood Glucose 
included clonidine $0.1 \mathrm{mg} \mathrm{PO} \mathrm{BID} \mathrm{and} \mathrm{diltiazem} 240 \mathrm{mg}$ PO daily. Actions included increasing clonidine to three times daily and ordering a blood count and serum chemistry.

A laboratory study done at the end of July, 2008 showed FBG $162 \mathrm{mg} / \mathrm{dL}$ (9 mmol/L), 2-hPPG $214 \mathrm{mg} / \mathrm{dL}(11.8 \mathrm{mmol} / \mathrm{L})$, $\mathrm{HbA}$ c 7.5\%, C-peptide $1.2 \mathrm{ng} / \mathrm{ml}(\mathrm{n}=0.8-3.1 \mathrm{ng} / \mathrm{ml}), \mathrm{BUN} 12$ $\mathrm{mg} / \mathrm{dL}$, serum creatinine $1.30 \mathrm{mg} / \mathrm{dL}$, and eGFR $>60 \mathrm{ml} / \mathrm{min}$. Hemoglobin was $17 \mathrm{~g} / \mathrm{dL}$. At this time he was considered to have developed diabetes based on 2-hPPG, but he had no discernible complications. Because a robust association exists between an elevated 2-hPPG and cardiovascular disorders (CVD) [3], it was felt that keeping his 2-hPPG under control with antidiabetic therapy was important. Thus he was prescribed glyburide $5 \mathrm{mg}$ PO after lunch and dinner. He was also prescribed enalapril, $5 \mathrm{mg} \mathrm{PO}$, daily to reduce hemoglobin which may further reduce $B P[4,5]$.

He was seen in the office in the first week of May, 2009. Sitting and standing BPs were much reduced. They were $120 / 70 \mathrm{mmHg}$ and $130 / 70 \mathrm{mmHg}$, respectively. His 2-hPPG was $92 \mathrm{mg} / \mathrm{dL}$ ( $5.1 \mathrm{mmol} / \mathrm{L})$, eGFR $>60 \mathrm{ml} / \mathrm{min}$, and hemoglobin $14 \mathrm{~g} / \mathrm{dL}[4,5]$. The therapy was working perfect for him. Diabetes was not considered by previous physicians and blood pressures were not under control however, glycemia and hypertension were brought under control which will reduce his risk of CVD.

Patient \#3: This patient represents a typical case of druginduced hyperglycemia but not diabetes. A 65 y African American female was referred to the author for obesity, hypertension and renal insufficiency in October 2010. Her medication consisted of hydrochlorothiazide (HCTZ) 25 $\mathrm{mg}$ PO BID, slow K $10 \mathrm{mEq}$ PO BID, amlodipine $5 \mathrm{mg}$ PO $\mathrm{BID}$, amiloride $2.5 \mathrm{mg} P \mathrm{PO}$ daily and magnesium oxide 400 $\mathrm{mg}$ PO TID. She was taking all these medications since December of 2004. Her laboratory and change of therapy are shown in Table 2.

Normoglycemia observed in September and November, 2011 after discontinuation of Triam/HCTZ documents that the patient does not have diabetes. As of September 2011, 2-hPPG of $207 \mathrm{mg} / \mathrm{dL}$ was clearly due to HCTZ, and will probably be interpreted by many professionals as Type 2 diabetes. Glucose levels did not increase with use of bumetanide suggesting that thiazide diuretics most commonly produce hyperglycemia mimicking diabetes.

The next two patient examples will reinforce the problems with the diagnosis of Type 2 diabetes and hence-forth initiation of therapy with oral antidiabetic agents which eventually results in severe diabetes.

Patient \#4: Presented is a 33 y African American female weighing $240 \mathrm{lbs}$, diagnosed to have Type 2 diabetes and treated with OHA. She was first seen by the author (AKM) at the end of May, 2011 for diabetes. She gave a history of gestational diabetes and hypertension during each of two pregnancies. Both babies were big. She also gave history of seizures. Her medication at the time of her first visit were metformin $500 \mathrm{mg}$ PO BID, Lisinopril $20 \mathrm{mg}$ PO daily, Escitalopram $20 \mathrm{mg} P O$ daily, and Levetiracetum $1000 \mathrm{mg}$ PO BID (for seizures). Her laboratory from midApril 2011 showed FBG 134 mg/dL, HbA, 6.1\%, eGFR 87.3 $\mathrm{ml} / \mathrm{min}$. Her BUN and serum creatinine were 13 and 0.90 $\mathrm{mg} / \mathrm{dL}$, respectively. It was doubtful if she had diabetes, however she was advised to continue metformin until the next visit. Lisinopril was discontinued and atenolol $25 \mathrm{mg}$ PO daily was prescribed for blood pressure control. One month later, her FBG, 2-hPPG, and HbA, c were $126 \mathrm{mg} / \mathrm{dL}$, $179 \mathrm{mg} / \mathrm{dL}$ and $6.6 \%$ respectively. Renal function improved, BUN, serum creatinine and eGFR were $9 \mathrm{mg} / \mathrm{dL}, 0.70 \mathrm{mg} / \mathrm{dL}$ and $>110 \mathrm{ml} / \mathrm{min}$, respectively. It is evident that Lisinopril decreased renal function. Blood pressure was elevated

Table 2. Drug therapy, blood glucose, serum creatinine and potassium in a patient with drug-induced hyperglycemia (Patient 3)

\begin{tabular}{|c|c|c|c|c|c|c|c|}
\hline \multirow[t]{2}{*}{ Date } & \multirow{2}{*}{ Therapy } & \multicolumn{2}{|c|}{$\begin{array}{l}\text { Glucose } \\
(\mathrm{mg} / \mathrm{dL})\end{array}$} & \multicolumn{2}{|c|}{$\begin{array}{c}\text { Scr } \\
(\mathrm{mg} / \mathrm{dL})\end{array}$} & \multicolumn{2}{|c|}{$\begin{array}{r}\text { Serum K } \\
(\mathrm{mmol} / \mathrm{L})\end{array}$} \\
\hline & & $\mathbf{F}$ & 2-hPP & $\mathbf{F}$ & 2-hPP & $\mathbf{F}$ & 2-hPP \\
\hline Dec 2004 & HCTZ, SlowK, Amiloride, Amlodipine, MgOxide & 104 & ND & 1.2 & ND & 3.6 & ND \\
\hline Feb 2005 & Same as before & 117 & ND & 1.2 & ND & 3.9 & ND \\
\hline Oct 2010 & Triam+HCTZ (37.5/25) Mon,Wed,Fri & 123 & ND & 1.3 & ND & 4.1 & ND \\
\hline Sept 8, 2011 & Triam/HCTZ-NO Mon, Fri, Amlodipine 10 mg BID, Slow K & 123 & 207 & 1.3 & 1.47 & 4.2 & 3.4 \\
\hline \multicolumn{8}{|c|}{$\begin{array}{l}\text { She was told by her primary physician that she was developing diabetes. Action: Hold Triam/HCTZ, add Aldomet } 250 \mathrm{mg} \\
\text { TID to control blood pressure, reduce } \mathrm{KCl} \text { to } 20 \mathrm{mEq} \text { once daily. }\end{array}$} \\
\hline Sept 23, 2011 & Hold Triam/HCTZ & 114 & 144 & 1.2 & 1.3 & 4.0 & 4.0 \\
\hline \multicolumn{8}{|c|}{ Actions: 1) Triam + HCTZ discontinued, 2) Bemetamide $0.5 \mathrm{mg}$ PO Mon, Wed, Fri, 3) $\uparrow \mathrm{KCl} 20 \mathrm{mEq}$ BID } \\
\hline Nov 2011 & Bumetanide & 108 & 118 & 1.3 & 1.4 & 4.1 & 4.0 \\
\hline
\end{tabular}


but it was similar in both visits. Atenolol was increased to $50 \mathrm{mg} / \mathrm{dL}$. At her next office visit in mid-August, 2011, her FBG and 2-hPPG had increased to $343 \mathrm{mg} / \mathrm{dL}$ and $302 \mathrm{mg} / \mathrm{dL}$, respectively. Her BPs were further elevated. She was then-confirmed to have severe diabetes. The possibility remains that the beta blocker, atenolol, may have aggravated diabetes because of baseline elevated glucose levels [6] and probably because of impairment of pancreatic insulin release by a beta adrenergic receptor blocker [7]. In addition, she developed hypokalemia which further aggravates hyperglycemia [8]. Actions at this visit included discontinuation of metformin and initiation of Glargine insulin, 25 units after breakfast and 25 units after dinner [9]. She was advised to perform glucose monitoring at home upon wakening, 2 hours after each meal, and at bedtime. She was prescribed potassium chloride $20 \mathrm{mEq}$ PO BID and amiloride $2.5 \mathrm{mg}$ PO twice daily to minimize hypokalemia.

At a visit in early October 2011, her FBG and 2-hPPG were decreased to $177 \mathrm{mg} / \mathrm{dL}$, and $199 \mathrm{mg} / \mathrm{dL}$, respectively. Plasma renin and aldosterone were $0.1 \mathrm{ng} / \mathrm{ml} /$ hour and $4.7 \mathrm{ng} / \mathrm{dL}$ respectively. Her BP's were further elevated. Action included increase of atenolol to $50 \mathrm{mg}$ twice daily, discontinuation of amiloride, prescription of triamterene/ hydrochlorothiazide (Triam/HCTZ) 37.5/25 X1 PO daily, and increase of Lantus to 50 units after both breakfast and dinner. At a visit in late December 2011, her BP was still elevated at 140/100 $\mathrm{mmHg}$. FBG and 2-hPPG were reduced to $142 \mathrm{mg} / \mathrm{dL}$ and $206 \mathrm{mg} / \mathrm{dL}$, respectively. Clonidine 0.2 mg PO BID was added to her regimen. She returned at the end of February, 2012. Her diastolic BP remained elevated at $100 \mathrm{mmHg}$. Systolic BP ranged between 120 and 130 $\mathrm{mmHg}$. FBG and 2-hPPG further decreased to $146 \mathrm{mg} /$ $\mathrm{dL}$, and $189 \mathrm{mg} / \mathrm{dL}$, respectively. Her $\mathrm{HbA}$ c was $6.8 \%$ and average glucose $148 \mathrm{mg} / \mathrm{dL}$. The 2-hPP serum potassium was $3.5 \mathrm{mEq} / \mathrm{L}$. At this visit, action included discontinuation of Triam/HCTZ, prescription of chlorthalidone $12.5 \mathrm{mg}$ PO daily and spironolactone $12.5 \mathrm{mg}$ PO twice daily. She had to be hospitalized for markedly elevated glucose levels of FBG $366 \mathrm{mg} / \mathrm{dL}$ and 2-hPPG $529 \mathrm{mg} / \mathrm{dL}$ which resulted from intake of a large dose of steroid. She had developed dermatitis of the hands and went to a local hospital emergency room where she was prescribed high dose of prednisone. Her latest office visit in early June, 2012 showed marked improvement of glucose control. FBG, 2-hPPG and $\mathrm{HbA}$, were $130 \mathrm{mg} / \mathrm{dL}, 165 \mathrm{mg} / \mathrm{dL}$, and $7.7 \%$ respectively. Her insulin regimen consisted of Lantus 50 units after breakfast and 55 units after dinner ( 12 hours apart) and regular insulin on a sliding scale determined by finger-stick glucose levels 2-hPP and at bedtime. Her BP is normal and she takes atenolol $50 \mathrm{mg} \mathrm{BID}$, clonidine $0.2 \mathrm{mg}$ twice daily, chlorthalidone $12.5 \mathrm{mg}$ daily, and potassium chloride $20 \mathrm{mEq}$ BID. Her renal function was normal with eGFR $>110 \mathrm{ml} / \mathrm{min}$.

This patient illustrates that development of overt diabetes with insulin resistance may be an outcome in patients who had mildly elevated glucose levels initially but were treated with high doses of metformin which may cause exhaustion of beta cells over time and lead to overt diabetes [10].

Patient \#5: There is much to learn from this patient history. This 59 y African American male had his first visit with the author (AKM) in mid-February, 2012. He is a good historian and exhibits much responsibility in his care. In 2008, he was found to have coronary artery disease and treated with stent placement. During this hospital admission he was told that he had diabetes. He recalled that prior to hospitalization, he used to urinate frequently and drink a lot of fluids. He further gave an interesting family history of diabetes. His sister had diabetes and was treated with metformin and Lisinopril. She developed acute renal failure (ARF) and died. His mother had diabetes, was treated similarly to his sister and she also developed ARF and died. These family events made him cognizant of mistreatment of diabetes giving rise to renal failure and death.

At this visit his BP was mildly elevated, $160 / 80 \mathrm{mmHg}$. FBG was elevated at $162 \mathrm{mg} / \mathrm{dL}$ but renal function was normal. Medication consisted of amlodipine $5 \mathrm{mg}$ PO daily, metoprolol $25 \mathrm{mg}$ PO daily, and clopidogrel $75 \mathrm{mg}$ PO daily. He was taking, as prescribed, metformin 2000 mg PO daily, but discontinued six months prior to this visit because he felt that it was not helping to reduce his glucose level. He took Lisinopril $10 \mathrm{mg}$ PO daily until he ran out of it. He did not renew the prescription because he had read that Lisinopril causes kidney problems. At the first office visit, he was advised to stay off metformin and Lisinopril but take amlodipine and metoprolol for BP control and return to the office with required laboratory studies. Laboratory findings, BP recordings and therapy of his office visits from February to June, 2012 are presented in Table 3. He was seen in the office, with laboratory data, frequently with the goal of achieving BP and glucose control.

In this patient BP control was a real issue and required chlorthalidone to reduce BP. BP control was achieved, but at the expense of increased glucose level and reduction of renal function. Finally with a prescription of insulin, Glargine 25 units subcutaneously twice daily [9], his glucose levels decreased to normal and was accompanied by normal BP and improvement in renal function within a month (Table 3 ). He continued to take the thiazide diuretic, chlorthalidone, to keep BP under control.

Patient \#6: This patient was diagnosed to have diabetes and treated with OHA. Subsequently she was found not to have diabetes.

A 72 y white female was referred to author (AKM) with the question of whether she had diabetes. She was followed by a nephrologist, in the state of Kentucky, for kidney problems and was told that she had diabetes and placed on pioglitazone. Thirty-five years ago, she had an automobile 
Table 3. Blood pressure therapy, blood glucose levels and data from kidney function tests in a patient with hypertension and diabetes (Patient 5)

\begin{tabular}{|c|c|c|c|c|c|c|}
\hline \multirow{2}{*}{$\begin{array}{l}\text { Date } \\
2012\end{array}$} & \multirow{2}{*}{$\begin{array}{l}\text { Blood Pressure } \\
\text { (Sitting and Standing) } \\
\text { Systolic/Diastolic (mmHg) }\end{array}$} & \multirow{2}{*}{$\begin{array}{l}\text { FBG } \\
(\mathrm{mg} / \\
\mathrm{dL})\end{array}$} & \multirow{2}{*}{$\begin{array}{l}\text { 2-hPPG } \\
\text { (mg/ } \\
\text { dL) }\end{array}$} & \multirow{2}{*}{$\begin{array}{c}\mathrm{HbA}_{1} \mathrm{c} \\
(\%)\end{array}$} & \multicolumn{2}{|c|}{$\begin{array}{c}\mathrm{Scr} / \mathrm{eGFR} \\
(\mathrm{mg} / \mathrm{dL}-\mathrm{ml} / \mathrm{min})\end{array}$} \\
\hline & & & & & $\mathbf{F}$ & 2hPP \\
\hline \multirow[t]{2}{*}{ Feb 24} & $180 / 100$ & \multirow{2}{*}{168} & \multirow{2}{*}{124} & \multirow{2}{*}{6.5} & 1.64 & 1.65 \\
\hline & $160 / 100$ & & & & 46 & 46 \\
\hline \multicolumn{5}{|c|}{$\uparrow$ metoprolol to $50 \mathrm{mg}$ daily } & & \\
\hline \multirow[t]{2}{*}{ Apr 10} & $160 / 90$ & \multirow{2}{*}{140} & \multirow{2}{*}{148} & \multirow{2}{*}{6.8} & 1.74 & 1.88 \\
\hline & $150 / 100$ & & & & 43 & 39 \\
\hline \multicolumn{7}{|c|}{ Therapy: chlorthalidone $25 \mathrm{mg}$ daily Patient did not take metoprolol } \\
\hline \multirow[t]{2}{*}{ May 15} & $130 / 80$ & \multirow{2}{*}{307} & \multirow{2}{*}{357} & & 1.94 & 1.96 \\
\hline & $110 / 80$ & & & & 38 & 37 \\
\hline \multicolumn{7}{|c|}{ Therapy: Metoprolol $50 \mathrm{mg} / \mathrm{d}$, chlorthalidone $25 \mathrm{mg} / \mathrm{d}, \mathrm{KCl} 20 \mathrm{mEq} / \mathrm{d}$} \\
\hline \multicolumn{7}{|c|}{ Action: Reduced chlorthalidone to $12.5 \mathrm{mg} / \mathrm{d}$, increased $\mathrm{KCl}$ to $20 \mathrm{mEq}$ BID } \\
\hline \multirow[t]{2}{*}{ May 22} & $130-140 / 90$ & \multirow{2}{*}{286} & \multirow{2}{*}{289} & & 2.06 & 1.89 \\
\hline & $140 / 100$ & & & & 35 & 39 \\
\hline \multicolumn{7}{|c|}{ Therapy: As above Prescribed Lantus insulin 25 units after breakfast and 25 units after dinner } \\
\hline \multirow[t]{2}{*}{ June 22} & $120 / 82$ & \multirow{2}{*}{88} & \multirow{2}{*}{133} & & 1.62 & 1.67 \\
\hline & $110 / 80$ & & & & 47 & 45 \\
\hline Action: & nue current therapy & Lab ir & 6 weeks & & & \\
\hline
\end{tabular}

$\mathrm{Scr}=$ Serum creatinine $\mathrm{eGFR}=$ estimated glomerular filtration rate

accident which destroyed her left kidney. An ultrasound done in November of 2011 showed the absence of a left kidney. The right kidney was decreased in size with a moderately diffuse echogenic cortex. She told author (AKM) that she took pioglitazone for some time, then stopped. Her $\mathrm{BP}$ in the office were; sitting $150 / 90 \mathrm{mmHg}$ and standing $140 / 90 \mathrm{mmHg}$. Medications included levothyroxine 50 to $75 \mu \mathrm{g}$ PO daily, omeprazole 20 mg PO daily, allopurinol $100 \mathrm{mg}$ PO daily. Results from her laboratory studies are shown in Table 4.

Author (AKM) informed the patient that she currently did not have diabetes. However, low 2-hPPG (lower than FBG) with a high 2-hPP insulin response suggests that she may develop diabetes in the future. Thus she is advised to adopt a carbohydrate restricted 1800 calorie diabetes diet. The patient was pleased to know that she did not have diabetes.

Table 4. Blood glucose levels and data from kidney function tests in a patient incorrectly diagnosed with diabetes (Patient 6)

\begin{tabular}{lcccccccc}
\hline Dates & $\begin{array}{l}\text { Glucose } \\
(\mathbf{m g} / \mathbf{d L})\end{array}$ & \multicolumn{2}{c}{$\begin{array}{c}\text { Scr } \\
(\mathbf{m g} / \mathbf{d L})\end{array}$} & \multicolumn{2}{c}{$\begin{array}{c}\text { eGFR } \\
(\mathbf{m l} / \mathbf{m i n})\end{array}$} & $\begin{array}{c}\text { HbA }_{\mathbf{1}} \mathrm{c} \\
(\mathbf{\%})\end{array}$ & $\begin{array}{c}\text { Therapy } \\
\text { Change }\end{array}$ \\
\hline$\underline{2011}$ & $\mathrm{~F}$ & $2-\mathrm{hPP}$ & $\mathrm{F}$ & $2-\mathrm{hPP}$ & $\mathrm{F}$ & $2-\mathrm{hPP}$ & & None \\
\hline Nov 17 & 110 & 112 & 1.39 & 1.41 & 38 & 37 & 6.3 & \\
Dec 28 & 106 & 158 & 1.48 & 1.58 & 35 & 32 & & \\
\hline
\end{tabular}

Insulin: F 19.9 UIU/ml, 2-hPP 125.1 UIU/ml Renal function decreased. Reason: took Lisinopril from roommate for blood pressure control. Action: discontinue Lisinopril.

Prescription: amlodipine $5 \mathrm{mg}$ PO daily

\begin{tabular}{|c|c|c|c|c|c|c|c|c|}
\hline \multicolumn{9}{|l|}{$\underline{2012}$} \\
\hline Feb 7 & 113 & 120 & 1.36 & 1.30 & 39 & 41 & 6.5 & \multirow{2}{*}{ Small, frequent meals } \\
\hline July 11 & 114 & 94 & 1.21 & 1.23 & 44 & 44 & ND & \\
\hline Insulin: & UIU/ & $2 \mathrm{hPH}$ & 3 UIU & & & & & \\
\hline
\end{tabular}




\section{Discussion}

The diagnosis of Type 2 diabetes continues to be ambivalent in distinguishing fasting hyperglycemia from overt diabetes. Clearly, Type 2 diabetes means diabetes but many individuals with so-called Type 2 diabetes may not have diabetes as in patient \#6. Elevated fasting glucose levels are often due to antihypertensive therapy [11]. Type 2 diabetes was not defined in a statement by an American Association of Clinical Endocrinologists / American College of Endocrinology Consensus Panel on Type 2 diabetes mellitus [12]. This panel asserted that in order to minimize the risk of diabetes-related complications, the goal of therapy was to achieve an $\mathrm{HbA}_{1} \mathrm{c}$ of $6.5 \%$ or less. This panel considered monotherapy, dual therapy, and triple therapy including eight major classes of medications (biguanides, dipeptidylpeptidase-4 inhibitors, incretin mimetics, thiozolidinediones, a-glucosidase inhibitors, sulfonylureas, meglitinides, and bile acid sequestrants) and insulin therapy (basal, premixed and multiple daily injections) with or without orally administered medications. This panel did not define either Type 1 or Type 2 diabetes or relate glycemic levels associated with reduction of $\mathrm{HbA}_{1} \mathrm{c}$ with multiple oral medications or even with insulin.

Even the WHO report does not clarify Type 2 diabetes except stating that Type 2 diabetes is due to ineffective use of insulin [1]. The WHO report also states that Type 2 diabetes represents $90 \%$ of diabetes cases worldwide and treatment may involve lifestyle changes and weight loss alone, or oral medications or even insulin injection. The report does not specify the basis of different treatment categories (Type 1 or Type 2 diabetes) leaving the treating physicians in an indecisive state in the delivery of patient care.

The diagnosis of Type 2 diabetes is very commonly used in the media which makes most everyone think that diabetes is epidemic, but it is not. Why? Most individuals with the diagnosis of Type 2 diabetes have either elevated FBG as stated earlier, or mildly increased $\mathrm{HbA}_{1} \mathrm{c}$, for instance 6.5 to $7 \%$. The 2-hPPG or OGTT is rarely done to document or exclude diabetes (Table 5). A most important aspect in this article is that the patients presented, who have uncontrolled Type 2 diabetes, also have severe hypertension. They were most commonly prescribed a thiazide diuretic such as $\mathrm{HCTZ}$, Triam/HCTZ, or chlorthalidone to control their hypertension [11]. Thiazide diuretics commonly increase FBG and $\mathrm{HbA} \mathrm{c}_{1}$, but rarely increase 2-hPPG [8]. Thiazide diuretics increase glucose levels because of volume depletion, hypokalemia, or by other mechanisms not yet elucidated [8].

Thus the complications including worsening of diabetes noted in patients \#4 and \#5, as a result of previous therapy with $\mathrm{OHA}$, illustrates serious gaps in the understanding of the pathophysiology of diabetes. As a result, relevant testing, such as 2-hPPG or OGTT, to document diabetes and intention to initiate treatment with insulin to achieve adequate glycemic control, is lacking. Thus diagnosis of overt diabetes may be missed and omitting treatment with insulin could result in complications, namely end stage renal disease, heart attack and death or foot ulcer, gangrene and amputation. This again exhibits the inadequacy of the WHO report which does not specify which diabetes patients should be treated with which paradigm of therapy. Therefore authors feel compelled to make the following suggestions to adequately define diabetes and treat this metabolic disorder appropriately with a defined goal to prevent diabetic complications.

I. Type 2 diabetes is a misnomer. It does not convey any message to the patients including that diabetes is a serious disorder but with proper therapy, which is insulin, will permit healthy living with few or no complications.

II. When an elevated blood glucose level is found, professionals must ascertain that the patient is not receiving thiazide diuretics, steroid, calcineurin inhibitor or psychotropic drugs before labeling the patient with Type 2 diabetes, thereby spuriously inflating the perceived epidemic of diabetes. Once again, it is important to know that diuretics markedly increase blood glucose or exacerbate elevated baseline blood glucose [6].

III. An essential step to document or exclude diabetes is to order a basic metabolic panel at fasting and two hours after breakfast or lunch (2-hPP), and $\mathrm{HbA}_{1} \mathrm{c}$ which will allow the observation of glucose levels, renal function and electrolyte changes. Glucose levels at 2-hPP of $>200 \mathrm{mg} /$ $\mathrm{dL}(11.1 \mathrm{mmol} / \mathrm{L})$ is diagnostic of diabetes (Table 5); 2-hPPG $<200 \mathrm{mg} / \mathrm{dL}$ requires retesting to confirm or deny diabetes.

IV. The oral glucose tolerance test (OGTT) is the gold standard for the diagnosis of diabetes. Since OGTT is inconvenient for the patient as well as laboratory personnel, 2-h PPG after a major meal is the most sensitive alternative test for the diagnosis of diabetes and is more convenient for the patients and laboratory personnel [2](Table 5).

V. In a 4-hour oral glucose challenge test if the glucose level does not decrease to less than $200 \mathrm{mg} / \mathrm{dL}$ by the $4^{\text {th }}$ hour, the cornerstone of therapy is insulin. On the other hand, if the glucose level in the $2^{\text {nd }}$ to $4^{\text {th }}$ hour decreases to

Table 5. Sensitivity and specificity of fasting plasma glucose to diagnose Type 2 diabetes (US population aged 40 - 69 years)

\begin{tabular}{lccc}
\hline & $\begin{array}{c}\text { Sensi- } \\
\text { tivity } \\
(\%)\end{array}$ & $\begin{array}{c}\text { Speci- } \\
\text { ficity } \\
(\%)\end{array}$ & $\begin{array}{c}\text { Positive } \\
\text { Predictive } \\
\text { Value }\end{array}$ \\
\hline 2h post glucose challenge & & & \\
Plasma Glucose & & & \\
\hline$>200 \mathrm{mg} / \mathrm{dL}(>11.1 \mathrm{mmol} / \mathrm{L})^{*}$ & 97 & 100 & 100 \\
Fasting Plasma Glucose & & & \\
$\geq 100 \mathrm{mg} / \mathrm{dL}(>5.5 \mathrm{mmol} / \mathrm{L})$ & 83 & 76 & 21 \\
$\geq 120 \mathrm{mg} / \mathrm{dL}(6.6 \mathrm{mmol} / \mathrm{L})$ & 54 & 98 & 76 \\
$\geq 140 \mathrm{mg} / \mathrm{dL}(7.7 \mathrm{mmol} / \mathrm{L})$ & 31 & 100 & 100 \\
\hline
\end{tabular}

${ }^{\star} 1 \mathrm{mM}=18 \mathrm{mg} / \mathrm{dL} \quad$ Adapted from Harris MI. Diabetes Care 1993; 16: 642-652 
the FBG level as in patient \#1, the recommended therapy is a 1600 to 1800 calorie diabetes diet. Oral hypoglycemic agents may be prescribed to reduce 1-hPPG for protection against cardiovascular risk $[3,13]$. It has been stated that isolated postprandial hyperglycemia ( $2 \mathrm{hPPG}>140 \mathrm{mg} / \mathrm{dL}$ ) along with normal FBG $(<110 \mathrm{mg} / \mathrm{dL})$ and normal $\mathrm{HbA}_{1} \mathrm{C}$ $(<6.1 \%)$, is associated with a two-fold increased risk of death from cardiovascular disease [13].

Evidence is meager with regard to the relationship between 2-hPPG and other disorders such as nephropathy. To obviate the dilemma between FBG and 2-hPPG, we innovated the factor of dglucose (2-hPPG - FBG) and found excellent correlation between dglucose and serum creatinine and eGFR with 2-hPPG > $200 \mathrm{mg} / \mathrm{dL}$ ( $11.1 \mathrm{mmol} / \mathrm{L})$. In patients whose $2 \mathrm{hPPG}$ is greater than $200 \mathrm{mg} / \mathrm{dL}$, for every $100 \mathrm{mg} /$ $\mathrm{dL}$ increase in dglucose, serum creatinine increases by 0.11 $\mathrm{mg} / \mathrm{dL}$ and deGFR (2hPPG - FBG) decreases by $3.73 \mathrm{ml} / \mathrm{min}$; while in patients whose $2 \mathrm{hPPG}$ is $<200 \mathrm{mg} / \mathrm{dL}$ for every 100 $\mathrm{mg} / \mathrm{dL}$ increase in dglucose little change was seen in $\mathrm{dScr}$ $(-0.04 \mathrm{mg} / \mathrm{dL}) . \mathrm{HbA}, \mathrm{c}$ was poorly correlated with fasting renal function parameters and showed low $r$ and insignificant $p$ values [14]. In another study, FBG and $\mathrm{HbA}_{1} \mathrm{c}$ were found to be less sensitive than $2 \mathrm{hPPG}$ in predicting retinopathy and nephropathy [15].

Finally, like these authors, other authors have felt disarray in the diagnosis and treatment of diabetes [16]. Saudek and colleagues have concluded in their article "There are serious deficiencies in the current criteria for diagnosing diabetes, including the requirement that the patient be fasting and the lack of agreed upon screening criteria. These deficiencies make it unnecessarily inconvenient for clinicians to diagnose diabetes, thereby delaying the diagnosis and contributing to avoidable morbidity and mortality" [16].

\section{Competing interests}

The authors declare that they have no competing interests.

\section{Publication history}

Editor: Gaetano Santulli, Columbia

University Medical Center, USA.

Received: 14-Aug-2012 Revised: 09-Oct-2012

Accepted: 12-Oct-2012 Published: 30-Oct-2012

\section{References}

1. World Health Organization: Definition, diagnosis and classification of diabetes. WHO 1999. I Article

2. Harris MI: Undiagnosed NIDDM: clinical and public health issues. Diabetes Care 1993, 16:642-652. I Article| PubMed

3. Qiao Q, Pyorala K, Pyorala M, Nissinen A, Lindstrom J, Tilvis R, Tuomilehto J: Two-hour glucose is a better risk predictor for incident coronary heart disease and cardiovascular mortality than fasting glucose. Eur Heart J 2002, 23:1267-1275. | Article | PubMed

4. Susic D, Mandal AK, Kentera D: Heparin lowers the blood pressure in hypertensive rats. Hypertension 1982, 4:681-685. I Articlel PubMed

5. Susic D, Mandal AK, Kentera D: Hemodynamic effects of chronic alteration in hematocrit in spontaneously hypertensive rats. Hypertension 1984, 6:262-266. | Article | PubMed

6. Verdecchia P, Reboldi G, Angeli F, Borgioni C, Gattobigio R, Filippucci L, Norgiolini S, Bracco C, Porcellati C: Adverse prognostic significance of new diabetes in treated hypertensive subjects. Hypertension 2004, 43:963-969. | Article| PubMed

7. Santulli G, Lombardi A, Sorriento D, Anastasio A, Del Giudice C, Formisano P, Beguinot F, Trimarco B, Miele C, laccarino G: Age-related impairment in insulin release: the essential role of beta(2)-adrenergic receptor. Diabetes 2012, 61:692-701. I Article | PubMed

8. Mandal AK, Hiebert LM: Is diuretic-induced hyperglycemia reversible and inconsequential. J Diab Res Clin Met 2012, 1:1-5. | Article

9. Mandal AK, Neki NS: Diabetes: a pragmatic therapy with a goal to prevent end stage kidney disease and dialysis. Open J Int Med 2011, 1:80-92. | Article

10. Palumbo PJ: The case for insulin treatment early in type $\mathbf{2}$ diabetes. Cleve Clin J Med 2004, 71:385-386, 391-382, 394 passim. | Article| PubMed

11. Moser M: Is new-onset diabetes of clinical significance in treated hypertensive patients?--Con. J Clin Hypertens (Greenwich) 2006, 8:126-132. | Article| PubMed

12. AACE/ACE Consensus Statement: Endocr Pract 2009, 15:540-559. | $\underline{\text { Pdf }}$

13. Cavalot F, Petrelli A, Traversa M, Bonomo K, Fiora E, Conti M, Anfossi G, Costa G, Trovati M: Postprandial blood glucose is a stronger predictor of cardiovascular events than fasting blood glucose in type $\mathbf{2}$ diabetes mellitus, particularly in women: lessons from the San Luigi Gonzaga Diabetes Study. J Clin Endocrinol Metab 2006, 91:813-819. | Article| PubMed

14. Mandal AK, Hiebert LM, Khamis $\mathrm{H}$ : dGlucose is linked to renal function changes in diabetes. Diabetes Res Clin Pract 2011, 91:190-194. | Article l PubMed

15. McCance DR, Hanson RL, Charles MA, Jacobsson LT, Pettitt DJ, Bennett $\mathrm{PH}$, Knowler WC: Comparison of tests for glycated haemoglobin and fasting and two hour plasma glucose concentrations as diagnostic methods for diabetes. BMJ 1994, 308:1323-1328. | Article| PubMed Abstract | PubMed Full Text

16. Saudek CD, Herman WH, Sacks DB, Bergenstal RM, Edelman D, Davidson $\mathrm{MB}$ : A new look at screening and diagnosing diabetes mellitus. $J$ Clin Endocrinol Metab 2008, 93:2447-2453. | Articlel PubMed 